\title{
Recent Examination for Assessing Epidemiological Status of Schistosoma Mansoni in Plaine Orety, Urban Area of Libreville, Gabon, Central Africa
}

\author{
Rodrigue Mintsa Nguema ${ }^{1,2, *}$, Bertrand Mve Ondo ${ }^{2}$, Modeste Mabika Mamfoumbi ${ }^{2}$, \\ Aubin Armel Koumba ${ }^{1}$, Marielle Karine Bouyou Akotet ${ }^{2}$, Maryvonne Kombila ${ }^{2}$ \\ ${ }^{1}$ Research Institute in Tropical Ecology, National Center for Scientific and Technological Research, Libreville, Gabon \\ ${ }^{2}$ Department of Parasitology-Mycology, School of Medicine, University of Health Sciences of Libreville, Libreville, Gabon \\ Email address: \\ rodriguemintsa@yahoo.fr (R.M. Nguema), mvebertrand2000@yahoo.fr(B. M. Ondo), mabikmamfoumbi@yahoo.fr (M. M. Mamfoumbi), \\ aubinho25@yahoo.fr(A.A.Koumba),mariellebouyou@gmail.com(M. K. B. Akotet), valentine_favry@yahoo.fr(M.Kombila) \\ ${ }^{*}$ Corresponding author
}

\section{To cite this article:}

Rodrigue Mintsa Nguema, Bertrand Mve Ondo, Modeste Mabika Mamfoumbi, Aubin Armel Koumba, Marielle Karine Bouyou Akotet, Maryvonne Kombila. Recent Examination for Assessing Epidemiological Status of Schistosoma Mansoni in Plaine Orety, Urban Area of Libreville, Gabon, Central Africa. Central African Journal of Public Health. Vol. 4, No. 3, 2018, pp. 81-85.

doi: $10.11648 /$ j.cajph. 20180403.15

Received: February 8, 2018; Accepted: March 1, 2018; Published: August 9, 2018

\begin{abstract}
Schistosoma mansoni epidemiology is very uncertain in Gabon despite its wide distribution in Sub-Saharan African whereas knowledge of schistosomiasis endemicity setting has important implications for the national policy controls. To date only two cases of $S$. mansoni were diagnosed by the Department of Parasitology-Mycology (DPM), Libreville-Gabon between 1995 and 2009 and both came from Plaine Orety, an urban area of Libreville. As the result of this finding a survey that we report results here was conducted to determine the epidemiological status of $S$. mansoni in this site. Parasitological and malacological surveys were conducted prospectively from January to May 2012. Parasitological survey included people living in Plaine Orety (Libreville) area at least three months and aged from two years upwards. Stool examination was performed using Kato-Katz technique and malacological investigations were conducted in all the streams of this area for the same period to identify the intermediate snail host of $S$. mansoni. A total of 495 people were examined, of them 4 cases $(0.81 \%)$ were identified positive to $S$. mansoni with no significant influence of sex or age group $(p>0.05)$. Infected peoples said they never went out of the country but stayed in other regions of the country, i.e. Kango, Ovan, Lambaréné, Port-Gentil, Bitam and Fougamou. No intermediate snail host of human schistosomes has been identified in the whole surveyed water sites of Plaine Orety. Freshwater snails identified are: Lymnea sp, Physa sp, Melanoides $s p$ and Indoplanorbis exustus (intermediate snail host of cattle schistosomes in India). The finding of this study illustrate existing indigenous cases of $S$. mansoni in Libreville (Gabon) even if local active transmission area remains to be elucidate because of the absence of intermediate snail host Biomphalaria.
\end{abstract}

Keywords: Schistosomiasis, Schistosoma mansoni, Epidemiological Status, Intermediate Snail Host, Libreville, Gabon

\section{Introduction}

The genus Schistosoma includes 21 species but only onethirds are responsible for human schistosomiasis. Schistosomiasis remains a major public health problem with almost 240 million affected people and about 779 million at risk of infection with more than $90 \%$ living in sub-Saharan
Africa [1]. The disease occurs in 78 countries and territories in Africa, the Americas, the Eastern Mediterranean region, the Southeast Asian region and the Western Pacific [2]

Four species of Schistosoma are responsible for human schistosomiasis in Africa: Schistosoma mansoni, $S$. haematobium, S. intercalatum and S. guineensis [3]. Both $S$. mansoni and S. haematobium have a large geographical distribution in Africa, whereas S. intercalatum is limited to 
the Democratic Republic of the Congo and S. guineensis to the Lower Guinean Gulf [4]. In Gabon two species were commonly found: $S$. guineensis responsible for intestinal schistosomiasis and $S$. haematobium responsible for urogenital schistosomiasis $[5 ; 6,7]$. These two species affect about 500,000 peoples from the Gabon's 1.1 million estimated population [8]. The presence of natural hybrids between $S$. guineensis and $S$. haematobium has been suggested in some areas of the country: provinces of MoyenOgooué [9] and Estuaire [10], but not confirmed in recent molecular data [11].

The Gabonese ministry of health is planning the integration of Neglected Tropical Diseases (NTD) and Schistosomiasis control through mass drug administration. Therefore knowing the distribution of the targeted NTDs is essential for appropriate drug administration strategy. Whereas knowing schistosomiasis endemicity setting has important implications for the national policy controls, the transmission and distribution of $S$. mansoni in Gabon are uncertain despite its wide distribution in Sub-Saharan Africa including in all of Gabon surrounding countries, i.e. Cameroon, Guinea Equatorial, Republic of Congo [6, 12]. Indeed only few cases of $S$. mansoni infected people were reported without parasitological confirmation and with the absence of Biomphalaria snail in all the streams examined in Gabon $[13,14]$.

In order to determine $S$. mansoni transmission status in Gabon, we started our investigation with the few local cases of infection reported and identify the first probable site of transmission according to their laboratory records. The Department of Parasitology-Mycology (DPM), LibrevilleGabon, where an average of 1,000 stool samples are tested each year, reported two cases, the first in 1995 and the second in 2009. Both came from Plaine Orety, an urban area of Libreville the capital city of Gabon (DPM, unpublished data). From this finding, it was decided to focus the investigation exclusively in the Plaine Orety focus. The main objective of this investigation was to generate parasitological and malacological data in order to define the epidemiological status of $S$. mansoni in Libreville-Gabon. Implications of our findings for the monitoring and evaluation of schistosomiasis control strategies in Gabon are discussed hereafter.

\section{Material and Methods}

\subsection{Authorization and Ethical Assessment}

The study was authorized by the Ministry of Public Health. Two weeks before the surveys, the administrative chief of Plaine Orety was visited and the protocol was explained to him. The study team went back a week later to inform the whole population about schistosomiasis, the objectives and the procedure of the survey. Parents and children, of each family willing to participate, gave their oral consent and were assigned an identification number. Individuals tested positive were treated free of charge according to a national Policy.

\subsection{Study Area}

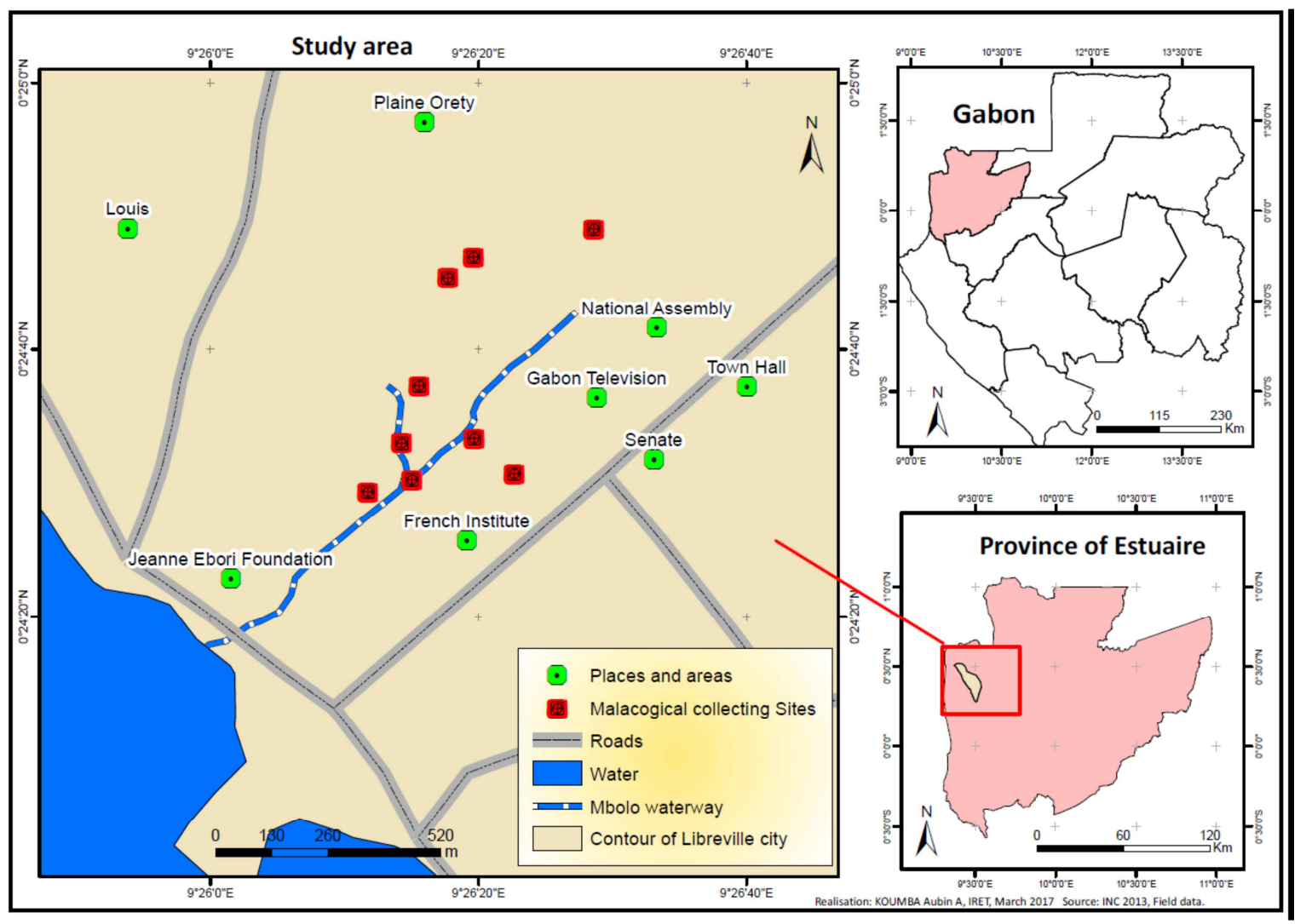

Figure 1. Map of the study area showing the waterway and the nine sites of the malacological surveys. 
The present study was conducted in Plaine Orety quarter, an urban area located within the 2nd borough of Libreville, capital of Gabon (Figure 1). Plaine Orety was a suspected area of $S$. mansoni transmission according to the DPM's archives (DPM, unpublished data). Indeed, the cases of infected $S$. mansoni people were reported living in the quarter which has a man-made stream of $2 \mathrm{~m}$ wide and $1.75 \mathrm{~m}$ depth of the Langoune River. This waterway was built to control flooding in the area. Due to the rising waters of the river in rainy seasons, the man-made stream becomes a suitable environment to freshwater snail. The waterway is connected with the sea water and a lot of fishing is therefore performed. It is also used for swimming and games for children at the expense of hygiene. There are latrines located around the waterway with the risk of contamination of water by fecal waste. The Plaine Orety population, about 10,000 people, has high unemployment rate and low family income, the main socio-economic indicator.

\subsection{Study Design and Sampling}

\subsubsection{Study Type, Period and Study Population}

The present survey is a prospective field cross-sectional study focuses on a non-probability sampling. It was carried out from January to May 2012. Study population involved all people of 2 years old and above residing in the study area for at least three months at the time of survey.

\subsubsection{Data Collection}

The Data collected included name, age, sex, address, parasitological test for $S$. mansoni and a catalog of freshwater snail encountered in the site.

For parasitological test, stool samples of each individual were collected from 8.00 to $12.00 \mathrm{~h}$ am in a $50 \mathrm{~mL}$ of plastic screw-cap vial and transported to the DPM for examination. Stool samples were examined for presence and number of $S$. mansoni eggs using the Kato-Katz technique. A single thick smear equivalent to $41.7 \mathrm{mg}$ of stool was analyzed for each stool sample. Eggs were counted by microscopy and intensity of infection was expressed as eggs per gram of feces (epg).

For malacological survey, freshwater snails were daily collected in nine sites of Plaine Orety canal for $1 \mathrm{~h}$ each by two study personnel using a stainless-steel strainer $(18 \mathrm{~cm}$ wide, $8 \mathrm{~cm}$ deep, $20 \mathrm{~cm}$ handle, and, $1 \mathrm{~mm}$ wide holes) attached to a handle. Submerged and emergent vegetation, as well as floating plants, were screened. For each site, collected snails were identified according to morphological criteria and tested for cercariae emergence.

\subsection{Data Analysis}

Data was reported on a Microsoft Excel 2007 worksheet for checking. Prevalence and intensity (including only the positives schoolchildren) of infection were calculated at overall, sex and age group level. Findings were presented in tabular format and the $\chi^{2}$ test was used to compare differences in prevalence by using $\mathrm{R}$ software version 3.2.2. The significance of tests was defined at $p<0.05$.

\section{Results}

A total of 495 (289 females and 206 males) peoples were examined. Participants' age ranges from 2 to 94 years with median age of 19 years. The age group ranging from 16 to 45 constitutes majority $209(42.22 \%)$ followed by the age group from 6 to $15: 145(29.29 \%)$, those $<6: 72(14.55 \%)$ and $>45$ years: $69(13.94 \%)$. From the 495 examined people, only 4 $(0.81 \%$; 95\% CI $0.22-2.06 \%)$ were positive for excretion of $S$. mansoni eggs in stool sample that were easily recognizable by the lateral position of their spur (Figure 2).

Positive cases were 3 female of 32; 38 and 45 years old and 1 male of 25 years old, no significant difference according to sex and age group ( $\mathrm{p}>0.05)$. (Table 1). Mean intensity of infection was $60 \pm 27.7(n=4)$ eggs per gram of stool.

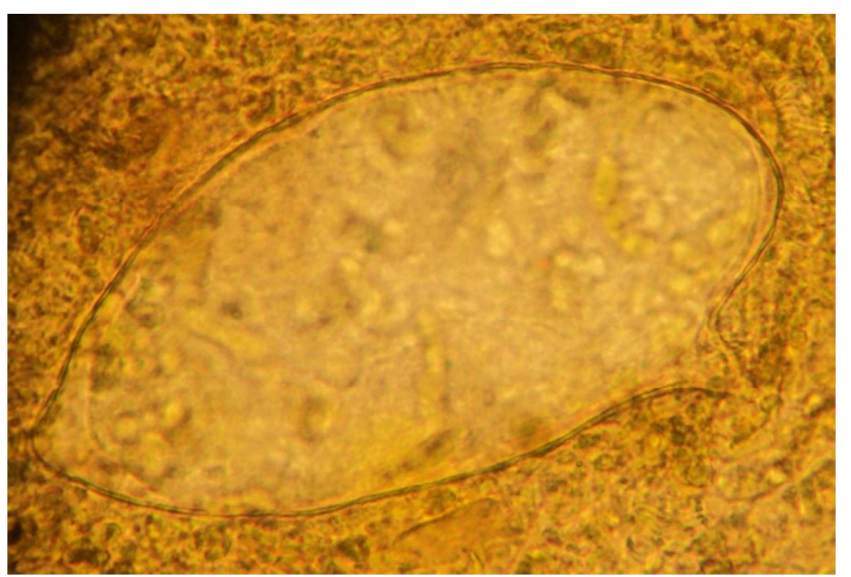

Figure 2. Picture of Schistosoma mansoni egg found in the stool of an inhabitant of Paine Orety, Libreville (Gabon).

Table 1. Infection to Schistosoma mansoni in Plaine Orety, Librevile (Gabon) tabulated by attributes of the study population. $N$ represents the number of individuals tested. Numbers in brackets represent the 95\% confidence intervals.

\begin{tabular}{lllll}
\hline & N & Number of cases & Percentage & P-value \\
\hline $\begin{array}{l}\text { Total } \\
\text { By Sex }\end{array}$ & 495 & 4 & $0.81[0.22-2.06]$ & \\
Female & 289 & 3 & & \\
Male & 206 & 1 & $1.04[0.21-3.00]$ & 0.6852 \\
By Age group (years) & & $0.49[0.00-2.67]$ & \\
$<6$ & 72 & 0 & $0[0.00-4.99]$ & \\
6 to15 & 145 & 0 & $0[0.00-2.51]$ & 0.787 \\
16 to 45 & 209 & 4 & $1.83[0.53-4.83]$ & \\
$>45$ & 69 & 0 & $0[0.00-5.21]$ & \\
\hline
\end{tabular}

Others helminths present in stools sample were $S$. guineensis (1.21\%; 95\% CI 0.45-2.62\%), Ascaris lumbricoides (1.62\% 95\% CI 0.70-3.16\%) Trichuris trichiura $(11.31 \%$; 95\% CI 8.66-14.44\%) and hookworms (2.02\%; 95\% CI 0.97-3.68\%).

Four (4) mollusk species have been identified in the whole nine examined sites. Among these species, no species of potential intermediate host of human schistosome were identified. Malacological fauna was mainly represented by 
Limnea sp; Melanoides sp and Physa sp. Indoplanorbis exustus, a species of intermediate snail host of cattle schistosome in India was identified in five of the nine sites examined, and no snail exhibited cercariae emergence.

\section{Discussion}

The results obtained indicate that infected cases of $S$. mansoni people are present in Plaine Orety, an urban area of Libreville, Gabon. Indeed, among the total of 495 samples tested, 4 $(0.81 \%)$ were positive to $S$. mansoni with no influence of sex or age group. This remains very low in comparison to those recorded in endemic areas. In Cameroon for example studies reported that prevalence was $24.1 \%$ in urban areas [15] and 10$49 \%$ in rural areas [16]. According to the prevalence of infection, Plaine Orety community can be classified as low-risk area according to the WHO classification [17] Moreover intensity of infection was light in our study, 60 epg. Whereas light-intensity infections alter the diagnosis of schistosomiasis and Kato-Katz aimed to underestimate the prevalence in this situation [18, 19]. Indeed, Kato-Katz sensitivity is very discussed in low endemicity areas because of day to day egg variations [20]. It is therefore advised to combine several techniques for diagnosis of schistosomiasis [21] as the more sensitive methods such as Point-of-Care Circulating Cathodic Antigen (POC-CCA) and Polymerase Chain Reaction (PCR) [22]. Furthermore, in our study, school-age children (aged 6-15 years), the most frequently infected age group, represents only $29 \%$ of total people sampling and no positive case was found in this group. We suggest to increase sampling in this age group.

No intermediate snail host for $S$. mansoni transmission was found from the nine sampling sites. Two hypotheses could justify this absence. First, malacological researches were not enough; it would be likely to conduct a study for a complete year because of annual dynamic of mollusk populations [23]. Next, infection was not occurred in Plaine Orety. Indeed, school-aged children, the most age group exposed at the risk of infection were not infected however positive cases were aged between 15 to 45 years. The interviews conducted with infected peoples revealed that none of them had stayed outside of Gabon. They indicated never being out of the country but have stayed in other regions of the country, i.e. Kango, Ovan, Lambaréné, Port-Gentil, Bitam and Fougamou where freshwater snail composition was not done.

\section{Conclusion}

Schistosomiasis due to $S$. mansoni is a public health problem in Central Africa. Epidemiological data gathered in this study has shown the presence of indigenous cases of $S$. mansoni in Libreville (Gabon). However, the question of transmission area remains to be elucidated because no intermediate snail host of $S$. mansoni was found in all streams of study site. Prospects should focus: firstly on the malacological research that need to be conducted during at least 12 consecutive months both in Plaine Orety and in other parts of Libreville and Gabon, including those where the infected S. mansoni patients were staying. Secondly, the use of more sensitive methods such as POC-CCA and PCR for parasitological diagnosis should be considered.

The findings from this study provide important epidemiological information on schistosomiasis due to $S$. mansoni. This provides the baseline data of schistosomiasis endemicity in the area thus represents an opportunity to Gabon to monitor for changes if control measures are implemented in order to align with the WHO objectives for schistosomiasis control or elimination as public health problem.

\section{Authors' Contributions}

RMN and MK conceptualized the study; RMN, BMO and MMM collected data; RMN and AK analyzed the data; RMN wrote the manuscript; MKBA and MK facilitated the structuring of the study and provided relevant documents. All authors readied and approved the final manuscript.

\section{Competing Interests}

The authors declare that no conflict of interest exists.

\section{Acknowledgements}

This work received financial support from the University of Health Sciences of Libreville and ISID/ESCMID/2013 Fellowship award for the project, "Schistosomiasis in Estuaire province of Gabon: what is the situation?," at the Université de Perpignan in Perpignan, France. We would like to thank peoples of Plaine Orety for their cooperation; this included the two chiefs of quarter for their administrative assistance. We are thankful to Lambert Ndong Obiang, JeanBlaise Medang and Jean-Charles Etho for technical assistance. We are very thank to Kysito Ogoussan for comments and editing to the manuscript.

\section{References}

[1] Steinmann P, Keiser J, Bos R, Tanner M and Utzinger J. Schistosomiasis and water resources development: systematic review, meta-analysis, and estimates of people at risk. Lancet Infect Dis 2006, 6: 411-425.

[2] World Health Organization. Schistosomiasis, progress report 2001-2011 and strategic plan 2012-2020. WHO, 2013.

[3] Kane RA, Southgate VR, Rollinson D, et al. A phylogeny based on three mitochondrial genes supports the division of Schistosoma intercalatum into two separate species. Parasitol 2003, 127(2):131-137.

[4] Pages JR, Jourdane J, Southgate VR, Tchuem-Tchuenté LA. Reconnaissance de deux espèces jumelles au sein du taxon Schistosoma intercalatum (Fisher, 1934), agent de la schistosomose humaine rectale. Description de S. guineensis n. sp. In: Combes C, Jourdane J. (Eds) Taxonomie, écologie et évolution des métazoaires parasites (2). Perpignan: Presses Universitaires, 2003: 380. 
[5] Giles GC. Les bilharzioses au Gabon. Bull Soc Pathol Ex 1971, 64: 879-886.

[6] Doumenge JP, Mott KE, Cheung C, Villenave D, Chapuis O, Perrin MF, Reaud Thomas G. Atlas de la répartition mondiale des schistosomiases. Genève: CEGET-CNRS, 1987: 400.

[7] Mabika Mamfoumbi M, Moussavou Boussougou MN, Nzenze Afene S, et al. Prevalence evaluation of intestinal parasites in rural and sub-urban area in Gabon. Bull Med Owendo 2009, 12(34): 85-88.

[8] Chitsulo L, Engels D, Montresor A, Savioli L. The global status of schistosomiasis and its control. Acta Trop 2000, 77(1): 41-51.

[9] Burchard GD, Kern P. Probable hybridization between $S$. intercalatum and S. haematobium in Wertern Gabon. Trop Geo Med 1985, 37: 119-123.

[10] Richard Lenoble D, Kombila M, Duong TH and Gendrel D. Bilharziose à Schistosoma intercalatum, bilharziose récente et oubliée. Rev Prat 1993, 43: 432-439.

[11] Mintsa Nguema R, Mengue Ngou Milama K, Kombila M, et al. Morphometric and molecular characterizations of schistosome populations in Estuaire province Gabon. J Helminthol 2010, 84(1): 81-85.

[12] Brown DS, Sarfati C, Southgate VR, Ross GC and Knowles RJ. Observations on Schistosoma intercalatum in South-East Gabon. Z Parasitenkd 1984, 70: 243-253.

[13] Deschiens R and Poirier A. Aspects épidémiologiques et cliniques de la bilharziose à Schistosoma intercalatum au Gabon. Bull Soc Pathol Ex 1967, 60: 228-240.

[14] Mc Cullough FS. Les Schistosomiases en République du Gabon. Rapport de mission. Brazzaville: OMS, 1975.

[15] Njiokou F, Onguene Onguene AR, Tchuem Tchuente LA and Kenmogne A. Schistosomose urbaine au Cameroun: étude longitudinale de la transmission dans un nouveau site d'extension du foyer de schistosomose intestinale de Mélen, Yaoundé. Bull Soc Pathol Ex 2004, 97: 37-40.
[16] Tchuem Tchuente LA, Kamwa Ngassam RI, Sumo L, et al. Mapping of schistosomiasis and soil-transmitted helminthiasis in the regions of centre, East and West Cameroon. PLoS Neglected Trop Dis 2012, 6(3): 15-53.

[17] World Health Organization. Preventive Chemotherapy in human helminthiasis: coordinated use of anthelminthic drugs in control interventions. Geneva: WHO, 2006.

[18] Enk MJ, Lustosa Lima AC, Costa Drummond S, Torres Schall $\mathrm{V}$, and Zech Coelho PM. The effect of the number of stool samples on the observed prevalence and the infection intensity with Schistosoma mansoni among a population in area of low transmission. Acta Trop 2008, 108: 22-226.

[19] Gentile R, Gonçalves MML, Da Costa Neto SF, Da Costa MM, Peralta RHS and Peralta JM. Evaluation of immunological, parasitological and molecular methods for diagnosis of Schistosoma mansoni infection before and after chemotherapy treatment with praziquantel in experimentally infected Nectomys squamipes. Vet Parasitol 2011, 180: 243249.

[20] Braun-Munzinger RA and Southgate BA. Repeatability and reproducibility of egg counts of Schistosoma haematobium in urine. Trop Med Parasitol 1992, 43:149-54.

[21] Alarcon de Noya B, Ruiz A, Losada S, et al. Detection of Schistosomiasis cases in low-transmission areas based on coprologic and serologic criteria The Venezuelan experience. Acta Trop 2007, 103: 41-49.

[22] Obeng BB, Aryeetey YA, de Dood CJ, et al. Application of a circulating-cathodic-antigen (CCA) strip test and real-time PCR, in comparison with microscopy, for the detection of Schistosoma haematobium in urine samples from Ghana. Ann Trop Med Parasitol 2008, 102:625-33.

[23] Woolhouse ME, Chandiwana SK. Population dynamics model for Bulinus globosus, intermediate host for Schistosoma haematobium, in river habitats. Acta Trop 1990, 47(3): 151160. 